\title{
Comparison of [18F] NaF PET/CT Analysis Methods and Derivation of a Semi-population Input Function for Site Specific Measurements of Bone Formation in a Population With Chronic Kidney Disease Mineral and Bone Disorder
}

Marie Houmaa Vrist ( $\nabla$ marvri@rm.dk)

University Clinic of Nephrology and Hypertension, Gødstrup Hospital, and Aarhus University https://orcid.org/0000-0002-5556-0078

\section{Jesper Nørgaard Bech}

University Clinical Hospital in Białystok II Nephrology Clinic with Hypertension Treatment Unit and Dialysis Unit: Uniwersytet Medyczny w Bialymstoku II Klinika Nefrologii z Oddzialem Leczenia Nadcisnienia Tetniczego i Pododdzialem Dializoterapii

Thomas Guldager Lauridsen

Aalborg University Hospital: Aalborg Universitetshospital

Claire Anne Fynbo

Gødstrup Hospital

Jørn Theil

Aarhus University: Aarhus Universitet

\section{Research Article}

Keywords: NaF, PET/CT, Hawkins, Patlak, semi-population input function, CKD-MBD

Posted Date: July 7th, 2021

DOI: https://doi.org/10.21203/rs.3.rs-641228/v1

License: (c) (1) This work is licensed under a Creative Commons Attribution 4.0 International License. Read Full License 


\section{Abstract}

\section{Purpose}

Implementation and comparison of non-invasive dynamic and static whole-body (WB) [ $\left.{ }^{18} \mathrm{~F}\right] \mathrm{NaF}$ PET/CT scan methods to replace invasive bone biopsy, used for quantitative analysis of bone clearance in patients with chronic kidney disease - mineral and bone disorder (CKD-MBD).

\section{Methods}

Seventeen patients with CKD-MBD underwent a 60-minute dynamic scan followed by a 30-minute static WB scan. Tracer kinetics in four thoracic vertebrae were analyzed using non-linear regression and Patlak analysis using image-derived arterial input functions. We validated the use of a semi-population input function in this population.

\section{Results}

Skeletal plasma clearance $\left(\mathrm{K}_{\mathrm{i}}\right)$ from Patlak analyses correlated well with non-linear regression analysis, but $\mathrm{K}_{\mathrm{i}}$-results using Patlak analysis were lower compared to $\mathrm{K}_{\mathrm{i}}$-results using non-linear regression analysis. However, no significant difference was found between $\mathrm{K}_{\mathrm{i}}$ obtained by static WB scans and $\mathrm{K}_{\mathrm{i}}$ obtained by dynamic scans using non-linear regression analysis $(p=0.29)$.

\section{Conclusion}

Our results show good correlation between dynamic and static analysis of skeletal plasma clearance with no significant difference between the $\mathrm{K}_{\mathrm{i}}$-results obtained by non-linear regression analysis and the more clinically suitable static scan analysis method. We found lower $\mathrm{K}_{\mathrm{i}}$-results when Patlak analysis was applied. Thus, WB [18F]NaF PET/CT scans can be applied in future studies to measure $\mathrm{K}_{\mathrm{i}}$ in CKD-BMD patients, but the results should not be compared uncritically with results obtained by dynamic scans analysis.

\section{Background}

Fluorine-18 labelled sodium fluoride ( $\left.{ }^{18} \mathrm{~F}-\mathrm{NaF}\right)$ was introduced in the 1960 s as a bone-seeking tracer in nuclear medicine(1) and widely used for gamma camera bone scintigraphy, but was later replaced by Technetium-99m labelled diphosphonates in the 1970s. In the past decades, ${ }^{18} \mathrm{~F}-\mathrm{NaF}$ has been reintroduced in combination with PET/CT.

Chronic kidney disease (CKD) is associated with universal bone abnormalities (renal osteodystrophy) and disturbances in mineral metabolism leading to cardiovascular and extra skeletal calcifications. These processes are caused by common pathophysiological pathways and are defined as a systemic disorder named Chronic Kidney Disease - Mineral and Bone Disorder (CKD-MBD) (2). Even though bone-related complications have been known in CKD since 1883(3), the key to effective treatment and prevention remains to be found, with this shortcoming possibly attributed to the lack of non-invasive methods available for 
Today, bone biopsy is considered the gold standard for analysis (4), but it is invasive, unpleasant and not without risk to the patient. However, since the 1990s non-invasive ${ }^{18} \mathrm{~F}-\mathrm{NaF}$ PET/CT has shown good potential for monitoring CKD-MBD (5). Here ${ }^{18} \mathrm{~F}-\mathrm{NaF}$, administered as an intravenous bolus injection, diffuses from the plasma into the extra vascular compartment in bones from where it is further incorporated into the bone's hydroxyapatite skeleton as fluoroapatite (6).

The plasma clearance of ${ }^{18} \mathrm{~F}-\mathrm{NaF}$ to bone $\left[\mathrm{K}_{\mathrm{i}}\left(\mathrm{ml} \mathrm{min}^{-1} \mathrm{ml}^{-1}\right)\right]$ predominantly reflects changes in bone formation rate. Traditionally, non-linear regression analysis with the two-tissue compartment model (Fig. 1) originally described by Hawkins [7] or the Patlak multiple data point graphical method have been used to determine $\mathrm{K}_{\mathrm{i}}$ and other kinetic parameters using dynamic data acquisition $(7,8) . \mathrm{K}_{\mathrm{i}}$-values are shown to correlate well with turnover results obtained by bone biopsies (5). Both non-linear regression analysis and Patlak analysis require dynamic acquisition over a single field-of-view (FOV), typically of 60-minutes duration. Due to restrictions in the axial width $(16-25 \mathrm{~cm})$ of almost all but the most modern dynamic whole-body scanners, dynamic scans can examine only a selected region of the skeleton within a single FOV, with extended regions of interest requiring multiple scans and tracer injections. This is not only impractical in a clinical setting but will result in a high radiation dose to the patient. However, modern advances in PET/CT scanner functionality, combining an initial, short duration dynamic acquisition over the heart followed by a series of fast multiple whole-body scans are now available and may soon provide a solution to the problem of extended dynamic scanning. Previously, this limitation has been addressed through development of a simplified acquisition and analysis method in which a static, WB ${ }^{18} \mathrm{~F}-\mathrm{NaF}$ PET scan in combination with a standardized semi-population input function (SPIF), estimates $\mathrm{K}_{\mathrm{i}}$-values in multiple bone regions using a static scan analysis as described previously $(9,10)$. With this method it is possible to perform a 30-minute WB acquisition with site-specific bone analysis using a single tracer injection $(9,11$, 12).

To our knowledge a systematic study, including derivation of a population residual curve for CKD-MBD patients, has not previously been published. The objectives of this study were threefold: 1) implementation of ${ }^{18} \mathrm{~F}-\mathrm{NaF}$ PET/CT using the Hawkins method and Patlak analysis for dynamic studies of skeletal plasma clearance in our clinic for CKD-MBD patients, 2) derivation of a CKD-MBD population residual curve for subsequent SPIF construction in combination with venous blood samples to be used as the arterial input function (AIF) for static scan analysis in WB scans and, 3) comparison of WB scan $\mathrm{K}_{\mathrm{i}}$-results with $\mathrm{K}_{\mathrm{i}}$-results from dynamic scan analysis to validate the future usage of static scans in the CKD-MBD population.

\section{Materials And Methods}

\section{Subjects}

Thirty-four chronic dialysis patients (30-80 years) were included, of which 17 participants completed the study (hemodialysis $n=15$, peritoneal dialysis $n=2$ ). Exclusion criteria were pregnancy, participants who suffered from alcohol/drug abuse, allergy to ${ }^{18} \mathrm{~F}-\mathrm{NaF}$ or tetracycline, or in the past three months had had 
bone fracture, acute myocardial infarction, transitory cerebral ischemia, kidney transplant or parathyroidectomy. Table 1 shows demographics and Fig. 2 shows flowchart for inclusion.

Table 1

Demographics

\begin{tabular}{|ll|}
\hline Demographics $(\mathbf{n}=\mathbf{1 7})$ & \\
\hline Age, years & $62.5 \pm 10.1$ \\
\hline Female, \% $(\mathrm{n})$ & $29.4(5)$ \\
\hline Male, \% $(\mathrm{n})$ & $70.6(12)$ \\
\hline Body mass index $(\mathrm{BMI}), \mathrm{kg} / \mathrm{m}^{2}$ & $24(23-29)$ \\
\hline Dialysis duration, years & $2.0(0.5-3.0)$ \\
\hline Cause of kidney failure, \% $(\mathrm{n})$ & $23.5(4)$ \\
• Hypertension & $29.4(5)$ \\
• Diabetic nephropathy & $23.5(4)$ \\
• Polycystic kidney disease & $5.9(1)$ \\
- Glomerulonephritis & $17.6(3)$ \\
• Other/unknown & \\
\hline $\begin{array}{l}\text { Normal distributed data: mean } \pm \text { SD. Non-normal distributed data: median (25th percentile; } 75 \text { th } \\
\text { percentile) }\end{array}$ \\
\hline
\end{tabular}

During data analysis one patient had to be excluded due to very poor image quality resulting from severe obesity and three patients were excluded due to delayed bolus injection or problems with blood sampling.

\section{Image acquisition}

PET/CT images were acquired on a Siemens Biograph mCT-4R 64 slice PET/CT scanner with a $22 \mathrm{~cm}$ axial FOV. The participants were positioned with the heart and the thoracic vertebrae 7 through 10 (Th7 - Th10) centered in the FOV.

Following an intravenous bolus injection of $150 \mathrm{MBq}{ }^{18} \mathrm{~F}-\mathrm{NaF}$ flushed with $20 \mathrm{~mL}$ isotonic saline, a 60minute list-mode dynamic scan was acquired followed by a WB scan from the middle of the femur to the vertex of the skull acquired in 6-7 FOVs of 3 minutes per bed position.

\section{Image reconstruction}

PET images for dynamic analysis were re-binned into 50-time frames: $20 \times 3 \mathrm{~s}, 12 \times 5 \mathrm{~s}, 4 \times 30 \mathrm{~s}$ and $14 \times$ 240s. Reconstruction of PET scans was done using filtered back-projection with a Gaussian filter of $5 \mathrm{~mm}$ and matrix size of $256 \times 256$. 
Low-dose CT scans were performed, and the images reconstructed in three utilization-dependent series: 1) attenuation correction, 2) localization and identification of thoracic vertebrae in the dynamic scan and 3) localization of the relevant bone regions in the WB scan.

All dynamic images were automatically decay corrected to the study injection time (study reference time). Image data from the WB scan was automatically decay corrected to the start of the WB scan, on average 66 \pm 2 -minutes post injection, requiring additional decay correction to the study reference time for comparison with dynamic data.

\section{Blood samples}

Venous blood samples ( $5 \mathrm{~mL}$ ) were collected at $-5,30,40,50,60$ and 90 minutes after injection and thereafter centrifuged at $3000 \mathrm{rpm}$ for 10 minutes. The activity concentrations in $1 \mathrm{ml}$ of whole blood and plasma were measured in a well-counter (Perkin Elmer Wizard2 ${ }^{\circledR}-2480$ Automatic Gamma Counter, USA). The well-counter and PET/CT scanner were cross-calibrated. To convert measured activity from imagederived whole blood to plasma activity curves, plasma to whole blood activity ratios were calculated for each of the samples (Fig. 3).

\section{Image analysis}

The PMOD $®$ version 4.003 software (PMOD Technologies LLC, Switzerland) was used for non-linear regression analysis of the dynamic data as well as analysis of the static WB data.

The drawing of VOIs, for generation of time activity curves (TACs) from the cardiac left ventricle (LV) was facilitated by summing the relevant time frames with highest activity into one static frame. Contours of the activity within the LV were drawn using the hot contouring tool in PMOD, defined as a percentage of the maximum activity within a box VOI surrounding the LV (typically 45-65\%). Our low-dose CT-images, albeit of localization quality, did not allow for delineation of the ventricular cavity or the myocardial wall as the contrast between the blood-filled cavities and solid walls were non-existent.

For correction of partial volume effect (PVE) and activity spill-over/spill-in, VOI contours within the myocardial wall were manually drawn using the brush tool on at least 10 axial slices with a voxel-size of 3.2 $\times 3.2 \times 1.4 \mathrm{~mm}$.

Box VOls were fitted to the trabecular part of the vertebral bodies Th7-Th10, avoiding the endplates and the disk spaces using the CT images as a template. These VOIs were similar for both dynamic and WB studies.

TACs were derived in the PMOD View Module and transferred to the PMOD Kinetic Module for further analysis as described in detail below.

\section{Input functions for dynamic scan analysis}

Dynamic scan analysis used an image-derived arterial input function (IDAIF) from a VOI placed in the LV as described above. In PMOD we used a 3-exponential model with fitting of the curve data from peak-time and 
Errors due to counting efficiency, PVE and spill-over/spill-in of activity were corrected by calculation of the recovery coefficient $\beta$, as described by Cook et al. and Puri et al. $(10,13)$ :

$R_{L V}(t)=\beta \cdot C_{L V}(t)+(1-\beta) \cdot C_{B g}(\mathrm{t})($ Eq. 1$)$

where $R_{L V}$ is activity in the image-derived TAC obtained from the $L V, C_{B g}$ is the background activity concentration in the surrounding myocardium and $\mathrm{C}_{\mathrm{LV}}$ is the true activity concentration in the LV. $\mathrm{C}_{\mathrm{LV}}$ is approximated to activity in venous blood samples 30 minutes after injection (10). From (Eq. 1), $\beta$ can be estimated as the mean value of $\beta$-coefficients calculated from each of the paired image and blood sample data.

\section{Input functions for static scan analysis}

For analysis of the static WB-scannings, we used a 3-exponential-fit semi-population input function (SPIF) as previously described by Blake et al. (9).

The SPIF was a combination of a population residual curve scaled for the patient injected activity and added to the terminal exponential derived from the plasma samples. We defined both the 0 -60-minute SPIF for comparison with the dynamic IDAIFs and the 0-90-minute SPIF for use as input functions with static scan studies following the dynamic studies.

The population residual curve was derived from the IDAIFs scaled to a reference dose of $150 \mathrm{MBq}$ for each participant. The residual curve represents the sum of the early fast exponentials and was derived by subtracting the terminal exponential (all data values $\geq 30$ minutes after injection) from the entire imagederived curve. All residual curves were adjusted so that the times of peak count rate for all curves were coincident with the most frequent unadjusted peak time (16.5s). The residual curves were then averaged to define the population residual curve.

\section{Skeletal plasma clearance}

The skeletal plasma clearance $\left[\mathrm{K}_{\mathrm{i}}\left(\mathrm{ml} \mathrm{min}{ }^{-1} \mathrm{ml}^{-1}\right)\right]$ was calculated as the mean value of four thoracic vertebrae (Th7-Th10) for the systematic application of three different analytic methods as described below. No correction for delay was made as we found the delay to be of only a few seconds and attempts of correcting the very noisy data in the first few acquisition frames, failed to make data more consistent.

\section{Non-linear regression analysis}

PMOD software was used to perform two-tissue compartment dynamic analysis of NaF-turnover as described by Hawkins et al.(7). The exchange of ${ }^{18} \mathrm{~F}-\mathrm{NaF}$ between the compartments: plasma, extravascular and bone (Fig. 1) is described by the kinetic parameters $\mathrm{K}_{1}-\mathrm{k}_{4}$ and the parameter for regional skeletal plasma clearance $\mathrm{K}_{\mathrm{i}}$ is defined as:

$K_{i}=\frac{K_{1} k_{3}}{k_{2}+k_{3}}$. (Eq. 2) 
The fractional blood volume $\mathrm{V}_{\mathrm{B}}$ of the bone was fixed at $5 \%$ (5).

\section{Patlak analysis}

Assuming the efflux rate constant $\mathrm{k}_{4}$ to be negligibly small $\left(\mathrm{k}_{4} \approx 0 \mathrm{~min}^{-1}\right)$, the Patlak graphical analysis provides a simpler alternative analysis method for measuring $\mathrm{K}_{\mathrm{i}}$ as described by Eq. $3(8,14)$ :

$\frac{C_{\text {Bone }}(T)}{C_{\text {Plasma }}(T)}=K_{i} \frac{\int{ }_{0}^{T} C_{\text {Plasma }}(t) d t}{C_{\text {Plasma }}(T)}+V_{0} \cdot($ Eq. 3)

This equation approximates a straight-line fit with $\mathrm{K}_{\mathrm{i}}$ as the slope. $\mathrm{C}_{\mathrm{Bone}}$ and $\mathrm{C}_{\mathrm{Plasma}}$ are the respective concentrations of tracer bound in bone and freely diffusible in plasma at each time-point $(t)$. $V_{0}$ is the intercept of the ordinate and represents the apparent volume of distribution.

$\mathrm{K}_{\mathrm{i}}$ was calculated from the 60-minute dynamic PET/CT scan using a bone TAC and IDAIFs or SPIFs.

\section{Static scan analysis}

The static scan analysis requires a single data point using activity measured in a selected bone region combined with a previously determined value of the intercept $\left(\mathrm{V}_{0}\right)$ for calculation of the straight-line function with $\mathrm{K}_{\mathrm{i}}$ as the slope (11).

\section{Statistical analysis}

Normally distributed results are presented as mean \pm standard deviation (SD). Non-normally distributed data are presented as median (25th percentile; 75th percentile).

The paired t-test was used to compare means, where a two-tailed p-value of 0.05 or less was considered statistically significant. Correlations between $\mathrm{K}_{\mathrm{i}}$-values obtained using different analysis models were calculated by linear regression and presented by Pearson's correlation coefficient and the chi ${ }^{2}$-test was used to evaluate the fit of the input functions to an applied model. The percentage coefficient of variation of the population residual curves was obtained by dividing the SD by the population residual curve and the $95 \%$ confidence interval was estimated using a chi² distribution.

\section{Results}

\section{Input functions}

The mean plasma to whole blood ratio was $1.17 \pm 0.03$. The mean recovery-coefficients $\beta$ was $0.69 \pm 0.15$ when the IDAIF was obtained from TACs in the LV. Table 2 evaluates the IDAIF by comparing the terminal exponentials with the terminal exponential of the plasma samples and found no differences in activity values at all comparable time-points at 30-60-minute blood samples. The alignment between the terminal exponential from input functions derived by image and by blood samples is pictured in Fig. $3 a$. 
Table 2

Comparison of the terminal exponentials of blood samples and the terminal exponential of image-derived input curve

\begin{tabular}{|c|c|c|}
\hline & & $\begin{array}{l}\text { Blood sample derived terminal } \\
\text { exponential }\end{array}$ \\
\hline & & $30,40,50$, and $60 \mathrm{~min}$ \\
\hline \multirow[t]{4}{*}{$\begin{array}{l}\text { Image-derived terminal } \\
\text { exponential }\end{array}$} & $\begin{array}{l}\text { Mean difference }(\mathrm{kBq} / \mathrm{min}) \\
\pm \mathrm{SD}\end{array}$ & $-0.32 \pm 0.79$ \\
\hline & $\mathrm{p}$-value & 0.187 \\
\hline & Mean ratio \pm SD & $1.06 \pm 0.14$ \\
\hline & $\mathrm{p}$-value & 0.143 \\
\hline
\end{tabular}

The derived population residual curve is shown in Fig. 5a. The variation in the curve is illustrated by the SD of the residual curves in Fig. $5 b$ (plotted as the percentage of the total population residual curve). The highest SD was at the peak-time of the population residual curve with a SD of $30 \%(95 \% \mathrm{Cl} 21-52 \%)$ and an average SD of the entire curve of $15.8 \%$.

Table 3 shows the characteristic areas under the curve (AUC)-values of the various AlFs image derived compared with population residual curve adjusted with 30-60-minute or 30-90-minute blood samples. No difference was found between AUCs comparing IDAIF and SPIF. No difference was found between AUC of IDAIFs corrected with 30-60-minute blood samples compared with AUC of IDAIFs corrected with 30-90minute blood samples ( $p$-value: 0.09).

Table 3

Comparison input functions obtained by $\beta$-corrected image-derived arterial input functions (IDAIF) and semipopulation input functions

\begin{tabular}{|c|c|c|c|c|}
\hline & IDAIF & SPIF & IDAIF & SPIF \\
\hline & $\begin{array}{l}\beta \text {-corrected } \\
\text { and blood } \\
\text { samples }\end{array}$ & $\begin{array}{l}\text { Population residual and } \\
\text { blood samples ( } 30-60 \\
\text { min) }\end{array}$ & $\begin{array}{l}\beta \text {-corrected } \\
\text { and blood } \\
\text { samples }\end{array}$ & $\begin{array}{l}\text { Population residual and } \\
\text { blood samples (30-90 } \\
\text { min) }\end{array}$ \\
\hline & $(30-60 \mathrm{~min})$ & & $(30-90 \mathrm{~min})$ & \\
\hline$A U C \pm S D$ & $353 \pm 59$ & $348 \pm 74$ & $341 \pm 54$ & $331 \pm 70$ \\
\hline $\begin{array}{l}\text { - Percentage } \\
\text { difference (p- } \\
\text { value) }\end{array}$ & & $-1.4 \%(0.671)$ & & $-2.9 \%(0.315)$ \\
\hline
\end{tabular}

\section{Skeletal plasma clearance}


Figure 3 shows a typical bone TAC. Initially, the curve is poorly defined as frame counts are low. Uptake in bone rises significantly after a few minutes, but with a slowly declining rate towards the end of the examination.

\section{Non-linear regression analysis}

The rate constants $\left(\mathrm{K}_{1}-\mathrm{k}_{4}\right)$ determined using the two-tissue compartment model are shown in Table 4. The mean value of $\mathrm{k}_{4}$ was $0.005 \mathrm{~min}^{-1}$ indicating that - at least within the 60 -minute time frame of the dynamic study - the efflux of ${ }^{18} \mathrm{~F}-\mathrm{NaF}$ from the vertebrae is low, an important prerequisite for proper use of the Patlak analysis method.

Table 4

Results of non-linear regression analysis for the rate constants $\left(\mathrm{K}_{1-4}\right)$ using the two-tissue compartment model

\begin{tabular}{|lllll|}
\hline $\mathrm{K}_{1}$ & $\mathrm{k}_{2}$ & $\mathrm{k}_{3}$ & $\mathrm{k}_{4}$ & $\mathrm{Chi}^{2}$ \\
$\left(\mathrm{ml} \mathrm{min}^{-1} \mathrm{ml}^{-1}\right)$ & $\left(\mathrm{min}^{-1}\right)$ & $\left(\mathrm{min}^{-1}\right)$ & $\left(\mathrm{min}^{-1}\right)$ & \\
\hline $0.111 \pm 0.04$ & $0.366 \pm 0.26$ & $0.195 \pm 0.07$ & $0.005 \pm 0.005$ & $60.1 \pm 53.4$ \\
\hline
\end{tabular}

Goodness-of-fit for the curves was evaluated by chi²-test. Values from 12 scans are expressed as mean \pm SD. Image-derived AIFs (IDAIFs) were obtained from a TAC of left ventricle of the heart (LV)

\section{Patlak analysis}

All dynamic datasets analysed according to Eq. 3 showed excellent straight-line fits with linear correlation coefficients close to 1.0 (Average $\mathrm{R}^{2}=0.996 \pm 0.002$ ) (Fig. 4).

Table 5 compares $\mathrm{K}_{\mathrm{i}}$-values obtained from non-linear regression analysis and Patlak analysis using both IDAIFs and SPIFs. $\mathrm{K}_{\mathrm{i}}$-values were lower using the Patlak analysis compared with $\mathrm{K}_{\mathrm{i}}$-values obtained from non-linear regression analysis. No difference was found in $\mathrm{K}_{\mathrm{i}}$-values when IDAIFs or SPIFs were applied for Patlak analysis. 
Table 5

Comparison of $\mathrm{K}_{\mathrm{i}}$-values obtained by non-linear regression analysis with Ki-values obtained by Patlak analysis using various input functions or static scan analysis.

\begin{tabular}{|c|c|c|c|c|c|}
\hline & \multirow{2}{*}{$\begin{array}{l}\text { Non-linear } \\
\text { regression } \\
\text { IDAIF }\end{array}$} & \multicolumn{3}{|c|}{ Patlak analysis } & \multirow{2}{*}{$\begin{array}{l}\text { Static scan } \\
\text { SPIF } \\
\text { (blood samples } \\
30-90 \text { min) }\end{array}$} \\
\hline & & IDAIF & $\begin{array}{l}\text { SPIF } \\
\text { (blood samples } \\
30-60 \text { min) }\end{array}$ & $\begin{array}{l}\text { SPIF } \\
\text { (blood samples } \\
30-90 \mathrm{~min} \text { ) }\end{array}$ & \\
\hline 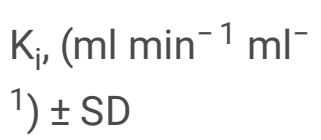 & $\begin{array}{l}0.0415 \pm \\
0.013\end{array}$ & $\begin{array}{l}0.0337 \\
\pm 0.009\end{array}$ & $0.0340 \pm 0.008$ & $0.0346 \pm 0.009$ & $0.0395 \pm 0.011$ \\
\hline $\begin{array}{l}\text { - Percentage } \\
\text { difference (P- } \\
\text { value) }\end{array}$ & - & $\begin{array}{l}-18.8 \% \\
\left(<0.01^{*}\right)\end{array}$ & $\begin{array}{l}-18.1 \%(< \\
\left.0.01^{\star}\right)\end{array}$ & $\begin{array}{l}-16.6 \%(< \\
\left.0.01^{*}\right)\end{array}$ & $-4.8 \%(0.29)$ \\
\hline $\mathrm{V}_{0} \pm \mathrm{SD}$ & - & $\begin{array}{l}0.39 \pm \\
0.17\end{array}$ & $0.52 \pm 0.25$ & $0.64 \pm 0.27$ & 0.64 \\
\hline
\end{tabular}

Comparison of $\mathrm{K}_{\mathrm{i}}$-results between non-linear regression analysis and Patlak analysis using $\beta$-corrected IDAIF in combination with 30-90 min blood samples (Fig. 6a), shows a statistically significant linear correlation $\left(R^{2}=0.92, p<0.001\right)$. Similarly, a statistically significant correlation was found between non-linear regression analysis and Patlak analysis $K_{i}$-values using $\beta$-corrected IDAIF plus 30-60 min blood samples $\left(R^{2}=0.93, p<\right.$ $0.001)$.

\section{Static scan analysis}

Table 5 shows no difference between $\mathrm{K}_{\mathrm{i}}$-values obtained by static scan analysis and in $\mathrm{K}_{\mathrm{i}}$-values obtained by dynamic non-linear regression. Table 6 shows $\mathrm{K}_{\mathrm{i}}$-values analysed by static scan analysis were higher compared with dynamic $\mathrm{K}_{\mathrm{i}}$-values analysed by Patlak analysis, but with a good correlation. 
Table 6

$\mathrm{K}_{\mathrm{i}}$-results obtained from static scan using the static scan analysis compared with $\mathrm{K}_{\mathrm{i}}$-results obtained from dynamic scan using Patlak analysis

\begin{tabular}{|c|c|c|c|c|c|c|c|c|}
\hline Scan & $\begin{array}{l}\text { First and } \\
\text { second } \\
\text { exponential }\end{array}$ & $\begin{array}{l}\text { Terminal } \\
\text { exponential }\end{array}$ & $\begin{array}{l}V_{0} \\
(\%)\end{array}$ & $\begin{array}{l}\mathrm{K}_{\mathrm{i}} \\
(\mathrm{ml} \\
\mathrm{min}^{-1} \\
\left.\mathrm{ml}^{-1}\right)\end{array}$ & $\begin{array}{l}\text { Percentage } \\
\text { difference }\end{array}$ & $\begin{array}{l}\mathrm{p}- \\
\text { value }\end{array}$ & $\mathbf{R}$ & $\begin{array}{l}\text { p- } \\
\text { value }\end{array}$ \\
\hline $\begin{array}{l}\text { Dynamic, } \\
\text { Patlak }\end{array}$ & $\begin{array}{l}\text { Population } \\
\text { residual }\end{array}$ & $\begin{array}{l}\text { Blood } \\
\text { samples } \\
30-90 \mathrm{~min}\end{array}$ & 64 & $\begin{array}{l}0.0346 \\
\pm 0.009\end{array}$ & - & - & - & - \\
\hline \multirow[t]{2}{*}{ Static } & \multirow[t]{2}{*}{$\begin{array}{l}\text { Population } \\
\text { residual }\end{array}$} & \multirow{2}{*}{$\begin{array}{l}\text { Blood } \\
\text { samples } \\
30-60 \text { min }\end{array}$} & 43 & $\begin{array}{l}0.0399 \\
\pm 0.010\end{array}$ & $+15 \%$ & $\stackrel{<}{0.001 *}$ & 0.930 & $<.001 *$ \\
\hline & & & 52 & $\begin{array}{l}0.0390 \\
\pm 0.010\end{array}$ & $+13 \%$ & $0.002^{\star}$ & 0.931 & $<.001 *$ \\
\hline \multirow[t]{2}{*}{ Static } & \multirow[t]{2}{*}{$\begin{array}{l}\text { Population } \\
\text { residual }\end{array}$} & \multirow{2}{*}{$\begin{array}{l}\text { Blood } \\
\text { samples } \\
30-90 \text { min }\end{array}$} & 43 & $\begin{array}{l}0.0419 \\
\pm 0.011\end{array}$ & $+21 \%$ & ¿. $001 *$ & 0.940 & $<.001 *$ \\
\hline & & & 64 & $\begin{array}{l}0.0395 \\
\pm 0.011\end{array}$ & $+14 \%$ & $0.001^{\star}$ & 0.942 & $<.001 *$ \\
\hline \multicolumn{9}{|c|}{$\begin{array}{l}\text { Mean values } \pm \text { SD are presented from } 12 \text { scans }(T h 7-10) \text {. Three different assumptions of } V_{0} \text { are applied } \\
\text { and compared with Patlak analysis } \mathrm{K}_{\mathrm{i}} \text {-values obtained using dynamic scans. Pearson's correlation } \\
\text { coefficient }(\mathrm{R}) \text {, * } \text { Level of Statistically significance: } p<0.05\end{array}$} \\
\hline
\end{tabular}

Figure $6 \mathrm{~b}$ shows statistically significant correlation between dynamic Patlak analysis and static scan analysis of mean $\mathrm{K}_{\mathrm{i}}$-values using SPIF using 30-90-minute blood samples $(R=0.94, p<0.001)$. A significant correlation was also observed when using 30-60-minute blood samples $(R=0.87, p<0.001)$.

\section{Discussion}

Methods for assessing skeletal health which can replace the gold standard bone biopsy are sorely needed in the clinical CKD-MBD setting e.g., effective bone treatment may be withheld if a patient is suspected of having adynamic bone disease. Access to non-invasive diagnostic methods to confirm or negate this would be an important clinical gain. This study implements both dynamic and static ${ }^{18} \mathrm{~F}-\mathrm{NaF}$ PET/CT imaging using various analysis methods: non-linear regression, Patlak analysis, and static graphical analysis, as well as construction of a representative CKD-MBD SPIF. All methods presented are found suitable for skeletal plasma clearance evaluation, where the simplified static graphical analysis is most suitable for implementation in clinical practice. We found no difference in $\mathrm{K}_{\mathrm{i}}$-results obtained by dynamic non-linear regression or static scan analysis. Static WB ${ }^{18} \mathrm{~F}-\mathrm{NaF}$ PET/CT opens the possibility for a relatively easy clinical assessment of skeletal variables in CKD-MBD.

To some extent CKD-MBD is present in all patients suffering from severe kidney failure in need of dialysis treatment. Therefore, the present study includes chronic dialysis patients as representatives of the CKD-MBD Loading [MathJax]/jax/output/CommonHTML/fonts/TeX/fontdata.js 
population. The participants in the present study were mostly males $(70 \%)$ and diabetic nephropathy was the most common cause of kidney failure (29\%). Previous studies using ${ }^{18} \mathrm{~F}-\mathrm{NaF}$ PET/CT for dynamic bone examination have mostly studied female osteoporotic patients and excluded patients with CKD $(12,15)$. However, a recently published study of a CKD-MBD population also included $50 \%$ males with diabetic nephropathy as the most common cause of kidney failure (34\%) (16).

\section{Input functions for dynamic scan analysis}

The present study evaluates different input functions. The mean AUC of a $\beta$-corrected IDAIF has previously been shown to be comparable with the AUC from direct arterial sampling (13) and as such, the $\beta$-corrected IDAIF was chosen as our reference input function for comparison with results from other input functions. All IDAIFs were converted to plasma activity using the average plasma to whole blood ratio found by venous blood sampling as described by Cook et al. (10). In this present study, we find the plasma/whole blood ratio to be slightly lower, where some of the difference may be explained by renal anemia in the CKD-MBD population. As we did not have blood samples in the time period of $0-30$ minutes, we were unable to correct for changes in the plasma/whole blood ratio over time as done by Cook et al. (10).

The recovery coefficient $\beta$ was calculated to correct the IDAIF for the combined effects of counting efficiency, PVE and spill-over/spill-in of activity between activity in the lumen and background structures. We found the variation of this $\beta$-coefficient to be dependent on image quality and blood sampling errors. Hence, optimal blood sampling is particularly important to obtain a reliable $\beta$-correction. The present study found a much lower $\beta$-coefficient $(0.69 \pm 0.15)$ compared with previously published mean $\beta$-coefficient values $(0.97 \pm 0.54)$, in which the aorta was used for derivation of input functions (13). The reason for this is most probably our use of a large VOI $\left(\sim 20 \mathrm{~cm}^{3}\right)$ to define the LV input function with a representative sample of the inhomogeneous activity, as a VOI with borders close to the myocardial wall (3-6 $\mathrm{mm}$ separation) is subject to PVE and spill-over of activity in combination with myocardial movement (between 5-8 $\mathrm{mm}$ as reported by Cho et al, thus exposing it to activity in the myocardial wall (17). In future studies this should be remedied by use of a smaller VOI placed in the middle of the LV which is less subject to PVE and spill-over, but on the other hand, more dependent on correct placement around the highest activity in the inhomogeneous distribution of activity. In spite of this, as long as the (local) quantitatively correct $\beta$-correction value is used for the applied analysis protocol and imaging scanner, the $\beta$-correction method is shown to define the AUC of the IDAIF as good as the gold standard with direct arterial sampling (15). This is to be expected as the level of the terminal exponential of the input function is shown to account for $75 \%$ of the AUC of the input function in the first 60 minutes (9). Thus, a precise correction of the terminal exponential of the IDAIF is of highest interest.

To enable future static scan analysis of multiple bone regions, a SPIF was derived combining the population residual curve and venous blood samples to produce an AIF. No difference was found between AUCs of the SPIFs compared with AUCs of the IDAIFs (Table 3). This suggests it is feasible for a fully dynamic IDAIF to be replaced by a generalized SPIF for estimation of dynamic information in bone clearance studies, which is necessary for investigation of extended, multiple bone regions (Fig. 7b). 
$V_{0}$ is observed to vary with the choice of input function as shown in Table 5. Our Patlak analysis gives a mean $V_{0}$ value of $0.39 \pm 0.17$ when IDAIF is applied as input function. This value is comparable to the population value of 0.43 previously reported by Siddique et al (11) in a population of 10 women with osteoporosis. However, when SPIFs are used as input function for Patlak analysis, mean $\mathrm{V}_{0}$-values tend to be higher. For static analysis, Siddique et al have previously published a $\mathrm{V}_{0}$ of 0.46 when using a SPIF (18). Thus, our values are in the same range as previously published values.

The value of $\mathrm{V}_{0}$ is known to be skeletal site, treatment, and analysis model specific $(11,18,19)$. However, $\mathrm{K}_{\mathrm{i}}$ estimates have been shown to be relatively independent of the choice of $V_{0}$. $A 20 \%$ difference in $V_{0}$ resulted in only a $5 \%$ change in $\mathrm{K}_{\mathrm{i}}(11)$, making the static analysis robust for clinical use, despite variability in the population $\mathrm{V}_{0}$-value.

\section{Input functions for static scan analysis}

The rationale for using an average population curve calibrated by the individual patient's plasma-activity, is the assumption that the shape of each patient's input curves is similar, but the actual plasma-values may differ due to e.g. disease or treatment of the disease (12). It is this known change in an input function's AUC due to treatment, which is why a simpler analysis using Standard Uptake Values (SUV) cannot be applied for static scan analysis and why the actual input function needs to be included. Furthermore, using a SPIF instead of a fully obtained IDAIF for each examination, can reduce the effective scan time remarkably.

The standard deviation is generally high in the obtained population residual curve (Fig. 5). The highest SD was at the peak-time of the population residual curve with a SD of $30 \%(95 \% \mathrm{Cl} 21-52 \%)$ and an average SD of the entire curve of $15.8 \%$. These are comparable with the values of $26.4 \%(19.0-42.3 \%)$ previously published by Blake et al. [9]. However, in this study, the ${ }^{18} \mathrm{~F}-\mathrm{NaF}$ tracer was administered by manual bolus injection. It may be possible to produce a population residual curve with less variation using an automated injection system.

In the present study, time adjustment to common peak position of the residual curves to make the average population curve was performed by time-shifting the curves such that the frames with maximum activity coincide. This could be suboptimal since the temporal sampling is low and the actual peak position does not coincide with the exact frame position having the maximum activity, potentially resulting in an artificial elevation of the averaged peak. However, the actual peak value of the input function seems to have little importance when calculating $\mathrm{K}_{\mathrm{i}}$, which is instead highly dependent on a reliable input function AUC. The semi-population residual curves and IDAIF shows similar AUCs.

Overall, we found the CKD-MBD population residual curve comparable with the previously published population residual curve for osteoporotic patients.

\section{Skeletal plasma clearance}

Greatest variability in the bone TACs occurs in the initial portion of the curves caused by a combination of initial low activity and short time frames (Fig. 3). Other published studies have used an average TAC over all

Loading [MathJax]/jax/output/CommonHTML/fonts/TeX/fontdata.js ach frame; improving counting statistics but

Page 13/23 
lowering the time resolution and as such, may be counterproductive $(11,12)$. However, this problem does not affect Patlak analysis, as the data are sampled at later time-points between 14-60 minutes.

\section{Non-linear regression analysis}

The mean $\mathrm{K}_{\mathrm{i}}$-value was $0.042 \pm 0.01 \mathrm{ml} \mathrm{min}^{-1} \mathrm{ml}^{-1}$ applying IDAIFs in a two-tissue compartment model (Table 5).

The first quantitative ${ }^{18} \mathrm{~F}-\mathrm{NaF}$ study evaluating kinetics in renal osteodystrophy, reported a mean $\mathrm{K}_{\mathrm{i}}$-value of $0.071 \pm 0.03 \mathrm{ml} \mathrm{min}^{-1} \mathrm{ml}^{-1}$ (5). A reason for such a high value may be attributed to the fact, that $72 \%$ of the population studied had untreated secondary hyperparathyroidism. Correspondingly, a new study by Aaltonen et al reported a mean value of 0.067 in dialysis patients with high turnover bone disease and 0.038 in dialysis patients with low turnover bone disease (16).

In comparison, our value of $0.042 \mathrm{ml} \mathrm{min}^{-1} \mathrm{ml}^{-1}$ lies within the lower cut-off limit defined in the Aaltonen study and above the value reported for two patients with hyperparathyroidism as found by Schiepers et al. $\left(0.034 \mathrm{ml} \mathrm{min}^{-1} \mathrm{ml}^{-1}\right)$. Additionally, the latest study looking at $\mathrm{K}_{\mathrm{i}}$ related to Paget disease, has published a much higher mean value of $0.114 \mathrm{ml} \mathrm{min}^{-1} \mathrm{ml}^{-1}$ (20).

\section{Patlak analysis}

This study finds a statistically significant correlation between the $\mathrm{K}_{\mathrm{i}}$-values obtained using non-linear regression analysis and Patlak analysis (R: 0.92, p-value: 0.001) (Fig. 6a), similar to previously published values in a healthy female population and in a postmenopausal female population with osteoporosis $(15$, 21).

The mean $\mathrm{K}_{\mathrm{i}}$-value is $0.034 \pm 0.01 \mathrm{ml} \mathrm{min}{ }^{-1} \mathrm{ml}^{-1}$ using IDAIFs as input to the Patlak analysis. This is comparable to results published for a chronic dialysis population $\left(L_{1-4}\right)$ with a mean value of $0.039 \mathrm{ml} \mathrm{min}^{-}$

$1 \mathrm{ml}^{-1}$ and, as expected, higher than the mean value of $0.028 \mathrm{ml} \mathrm{min}^{-1} \mathrm{ml}^{-1}$ found for a hemodialysis population with suspected adynamic bone disease $\left(\mathrm{L}_{1-4}\right)(16,22)$.

The mean $\mathrm{K}_{\mathrm{i}}$-value is significantly lower when analyzed using the Patlak analysis than with non-linear regression analysis (Table 5). The mean average difference between $\mathrm{K}_{\mathrm{i}}$-values for the two methods is $-19 \%$. This difference varies and has previously been reported to be $-7 \%$ by Brenner et al, $-13 \%$ by Installé et al and $-23.7 \%$ by Puri et al. $(14,15,23)$.

It has been suggested that Patlak analysis results are lower than those derived from the two-tissue compartment model due to efflux of tracer from the bone during the scan. In previous studies, the Patlak plots often showed a small but obvious curvature with the slope decreasing slightly as time advances, which has been related to the efflux of tracer. If such efflux is present, it may be corrected by the method described by Siddique et al (18). 
However, in the present study this curvature of the Patlak plot was barely visible and all plots fit very well to a straight-line with regression coefficients close to 1 (Fig. 4). Combined with the small $k_{4}$-values of 0.005 with a high standard deviation of \pm 0.005 , a small tracer efflux can only in part explain the discrepancy between our NLR- and Patlak-results and we found it disproportionate to correct for such a small efflux in this study.

The Patlak analysis has been reported to be superior to the two-tissue compartment model for research purposes as it is computationally simpler and requires a lower number of participants to show a statistically significant result due to its small precision error $(14,21)$.

\section{Static scan analysis}

Using the static scan analysis with a SPIF as described above for the four vertebrae Th7-Th10 imaged in WB scans, we found the $\mathrm{K}_{\mathrm{i}}$-value to be $0.0395 \pm 0.011 \mathrm{ml} \mathrm{min}^{-1} \mathrm{ml}^{-1}$. Thus, no difference was found between the static $\mathrm{K}_{\mathrm{i}}$-results and the dynamic $\mathrm{K}_{\mathrm{i}}$-results obtained by linear regression. Unsurprisingly, the $\mathrm{K}_{\mathrm{i}}$-result in the present study is higher than the $\mathrm{K}_{\mathrm{i}}$-result from a previous published study in patients with suspected adynamic bone disease $\left(0.028 \pm 0.012 \mathrm{ml} \mathrm{min}^{-1} \mathrm{ml}^{-1}\right)$. For comparison, the $\mathrm{K}_{\mathrm{i}}$-result in a study of patients with osteoporosis was in the lower range with a value of $0.025 \pm 0.007 \mathrm{ml} \mathrm{min}^{-1} \mathrm{ml}^{-1}(21,22)$.

In the present study, comparing $\mathrm{K}_{\mathrm{i}}$-results from the static scan analysis with $\mathrm{K}_{\mathrm{i}}$-results from the Patlak analyses using the same input functions, resulted in $14 \%$ lower $\mathrm{K}_{\mathrm{i}}$-results $(\mathrm{p}<0.001)$ compared to the static $K_{i}$-results. Despite this, the correlation between the methods is very good $\left(R^{2}=0.942, P<0.001\right)$. However, this emphasizes the importance of using the same analysis method when comparing results of tracer kinetic parameters.

\section{Limitations of the study}

Limitations of this study include not having AIF data from direct arterial sampling as a gold standard to evaluate the validity of the IDAIFs and SPIFs; however as described above, venous blood samples can complement the arterial sampling curve at least after 30 minutes (10). Additionally, the averaging of the residual curves for construction of a population residual curve presented here is not optimal and should be refined in future studies.

In this study design, the static scan sequentially followed a 60-minute dynamic scan. For analysis of the static scan we included a 90-minute blood sample for construction of an input function that encompassed the complete static scan time resulting in an input curve ending at time-point 90-100 minutes post injection (p.i.) For this reason, even a small efflux might influence the Patlak plot/static scan analysis presented here and correction for efflux may be necessary. However, as our data showed high tracer uptake in bone within 30-60 min p.i., it seems prudent to perform future static scan studies between 30 and 60 minutes after tracer injection to ensure data will not be biased by potential efflux of tracer from bone.

Dynamic scanning in the clinical setting is generally restricted to a single bed position but may change in the future with the advent of new dynamic total body PET scanning. However, a low effective scan time ensured by a SPIF and acquisition of a simple static scan for use on older scanners, and those without total body 


\section{Conclusion}

Three different methods for analysis of skeletal plasma clearance in a population of CKD-MBD patients for both experimental and clinical use using ${ }^{18} \mathrm{~F}-\mathrm{NaF}$ PET/CT scan have been successfully implemented.

A dynamic scan protocol using the two-tissue compartment model with robust mean $\mathrm{K}_{\mathrm{i}}$ - and $\mathrm{K}_{1}-4_{\text {-values }}$ has been established and it is observed that resulting $\mathrm{K}_{\mathrm{i}}$-values using Patlak analysis are lower compared to values obtained from the two-tissue compartment model.

A CKD-MBD population residual curve and corresponding SPIF have been developed for use with WB $\mathrm{PET} / \mathrm{CT}$ scans, allowing site-specific measurements of bone formation in multiple regions. However, our findings suggest that it is not mandatory for disease-specific population residual curves to be obtained for analysis of $\mathrm{K}_{\mathrm{i}}$.

Of relevance for simple clinical implementation, $\mathrm{K}_{\mathrm{i}}$-values obtained using static WB scanning were found to show no significant difference to $\mathrm{K}_{\mathrm{i}}$-values obtained using non-linear regression analysis. Comparison with bone biopsy is required to further validate bone turnover measurements determined from ${ }^{18} \mathrm{~F}-\mathrm{NaF} \mathrm{PET} / \mathrm{CT}$ scans in CKD-MBD patients.

\section{Declarations}

\section{Funding}

This study was funded by the Danish Kidney Association's Research Fund, The Axel Muusfeldt Foundation and Health Research Foundation of the Central Denmark Region.

\section{Conflict of interest:}

The authors declare that they have no conflict of interest.

\section{Ethical approval:}

All procedures performed in studies involving human participants were in accordance with the ethical standards of the institutional and/or national research committee and with the 1964 Helsinki declaration and its later amendments or comparable ethical standards. The study was approved by the Regional Committee on Biomedical Research Ethics (case number: 1-10-72-340-16) and Danish Health and Medicines Authority, EudraCT number: 2016-005160-34.

\section{Consent to participate:}

Informed consent was obtained from all individual barticipants included in the study.

Loading [MathJax]/jax/output/CommonHTML/fonts/TeX/fontdata.js 


\section{Consent to publish:}

Informed consent was obtained from all participants regarding publishing of data.

\section{Author information}

\section{Affiliations}

University Clinic in Nephrology and Hypertension, Gødstrup Hospital, and Aarhus University, Denmark:

Marie Houmaa Vrist (Orcid-id: 0000-0002-5556-0078) and Jesper Nørgaard Bech (Orcid-id: 0000-0002-06051277)

Department of Nephology, Aalborg University Hospital, Denmark:

Thomas Guldager Lauridsen

Department of Nuclear Medicine, Gødstrup Hospital, Denmark:

Claire Anne Fynbo (Orcid-id: 0000-0002-2490-5491) and Jørn Theil (Orcid-id: 0000-0002-9211-9900)

Department of Clinical Medicine, Aarhus University: Jørn Theil (Orcid-id: 0000-0002-9211-9900)

Corresponding author: Marie Houmaa Vrist (Orcid-id: 0000-0002-5556-0078)

\section{Acknowledgements}

The authors thank Malene Skov Hansen and Mette Emtkjær Mølgaard for their invaluable help with the practical execution of the PET/CT scans and blood sample analyses.

\section{Authors' contribution}

Study design: MV, JT, CF, TGL, JB

Study execution: MV, TGL, CF, JB

Method implementation, creation \& validation of analysis tools: CF, JT

Image analysis: MV, JT, CF

Statistical analysis: MV

First draft: MV

Manuscript review: all authors

Loading [MathJax]/jax/output/CommonHTML/fonts/TeX/fontdata.js 


\section{References}

1. Blau M, Nagler W, Bender MA. Fluorine-18: a new isotope for bone scanning. Journal of nuclear medicine: official publication Society of Nuclear Medicine. 1962;3:332-4.

2. Moe S, Drueke T, Cunningham J, Goodman W, Martin K, Olgaard K, et al. Definition, evaluation, and classification of renal osteodystrophy: a position statement from Kidney Disease: Improving Global Outcomes (KDIGO). Kidney international. 2006;69(11):1945-53.

3. Lucas RC. On a form of late rickets associated with albuminuria, rickets of adolecents. Lancet. 1883;1:993-4.

4. KDIGO. 2017 Clinical Practice Guideline Update for the Diagnosis, Evaluation, Prevention, and Treatment of Chronic Kidney Disease-Mineral and Bone Disorder (CKD-MBD). Kidney international supplements. 2017;7(1):1-59.

5. Messa C, Goodman WG, Hoh CK, Choi Y, Nissenson AR, Salusky IB, et al. Bone metabolic activity measured with positron emission tomography and [18F]fluoride ion in renal osteodystrophy: correlation with bone histomorphometry. J Clin Endocrinol Metab. 1993;77(4):949-55.

6. Blau M, Ganatra R, Bender MA. 18 F-fluoride for bone imaging. New York:: W B Saunders; 1972. pp. 317.

7. Hawkins RA, Choi Y, Huang SC, Hoh CK, Dahlbom M, Schiepers C, et al. Evaluation of the skeletal kinetics of fluorine-18-fluoride ion with PET. Journal of nuclear medicine: official publication. Society of Nuclear Medicine. 1992;33(5):633-42.

8. Patlak CS, Blasberg RG, Fenstermacher JD. Graphical evaluation of blood-to-brain transfer constants from multiple-time uptake data. Journal of cerebral blood flow metabolism: official journal of the International Society of Cerebral Blood Flow Metabolism. 1983;3(1):1-7.

9. Blake GM, Siddique M, Puri T, Frost ML, Moore AE, Cook GJ, et al. A semipopulation input function for quantifying static and dynamic 18F-fluoride PET scans. Nucl Med Commun. 2012;33(8):881-8.

10. Cook GJ, Lodge MA, Marsden PK, Dynes A, Fogelman I. Non-invasive assessment of skeletal kinetics using fluorine-18 fluoride positron emission tomography: evaluation of image and population-derived arterial input functions. Eur J Nucl Med. 1999;26(11):1424-9.

11. Siddique M, Blake GM, Frost ML, Moore AE, Puri T, Marsden PK, et al. Estimation of regional bone metabolism from whole-body $18 \mathrm{~F}$-fluoride PET static images. Eur J Nucl Med Mol Imaging. 2012;39(2):337-43.

12. Frost ML, Siddique M, Blake GM, Moore AE, Schleyer PJ, Dunn JT, et al. Differential effects of teriparatide on regional bone formation using (18)F-fluoride positron emission tomography. Journal of bone mineral research: the official journal of the American Society for Bone Mineral Research. 2011;26(5):1002-11.

13. Puri T, Blake GM, Siddique M, Frost ML, Cook GJR, Marsden PK, et al. Validation of new image-derived arterial input functions at the aorta using 18F-fluoride positron emission tomography. S.I.]:: Lippincott; 2011. pp. 486-95. 
14. Brenner W, Vernon C, Muzi M, Mankoff DA, Link JM, Conrad EU, et al. Comparison of different quantitative approaches to 18F-fluoride PET scans. Journal of nuclear medicine: official publication Society of Nuclear Medicine. 2004;45(9):1493-500.

15. Puri T, Blake GM, Frost ML, Siddique M, Moore AE, Marsden PK, et al. Comparison of six quantitative methods for the measurement of bone turnover at the hip and lumbar spine using 18F-fluoride PET-CT. Nucl Med Commun. 2012;33(6):597-606.

16. Aaltonen L, Koivuviita N, Seppanen M, Tong X, Kroger H, Loyttyniemi E, et al. Correlation between (18)FSodium Fluoride positron emission tomography and bone histomorphometry in dialysis patients. Bone. 2020;134:115267.

17. Cho YH, Kang JW, Choi SH, Yang DH, Anh TTX, Shin ES, et al. Reference parameters for left ventricular wall thickness, thickening, and motion in stress myocardial perfusion CT: Global and regional assessment. (1873-4499 (Electronic)).

18. Siddique M, Frost ML, Moore AE, Fogelman I, Blake GM. Correcting (18)F-fluoride PET static scan measurements of skeletal plasma clearance for tracer efflux from bone. Nucl Med Commun. 2014;35(3):303-10.

19. Blake GM, Siddique M, Frost ML, Moore AE, Fogelman I. Imaging of site specific bone turnover in osteoporosis using positron emission tomography. Curr Osteoporos Rep. 2014;12(4):475-85.

20. Christiaan Schiepers JN, Guy Bormans J, Dequeker R, Bouillon L, Mortelmans. Alfons Verbruggen and Michel De Roo. Fluoride Kinetics of the Axial Skeleton Measured in Vivo with Fluorine-18-Fluoride PET. The Journal of Nuclear Medicin. 1997;38(12):1970-6.

21. Siddique M, Frost ML, Blake GM, Moore AEB, Al-Beyatti Y, Marsden PK, et al. The precision and sensitivity of (18)F-fluoride PET for measuring regional bone metabolism: a comparison of quantification methods. 2011. p. 1748-55.

22. Frost ML, Compston JE, Goldsmith D, Moore AE, Blake GM, Siddique M, et al. (18)F-fluoride positron emission tomography measurements of regional bone formation in hemodialysis patients with suspected adynamic bone disease. Calcif Tissue Int. 2013;93(5):436-47.

23. Installé J, Nzeusseu A, Bol A, Depresseux G, Devogelaer J-P, Lonneux. M. ${ }^{18}$ F-Fluoride PET for Monitoring Therapeutic Response in Paget's Disease of Bone. J Nucl Med. 2005;46(10).

\section{Figures}
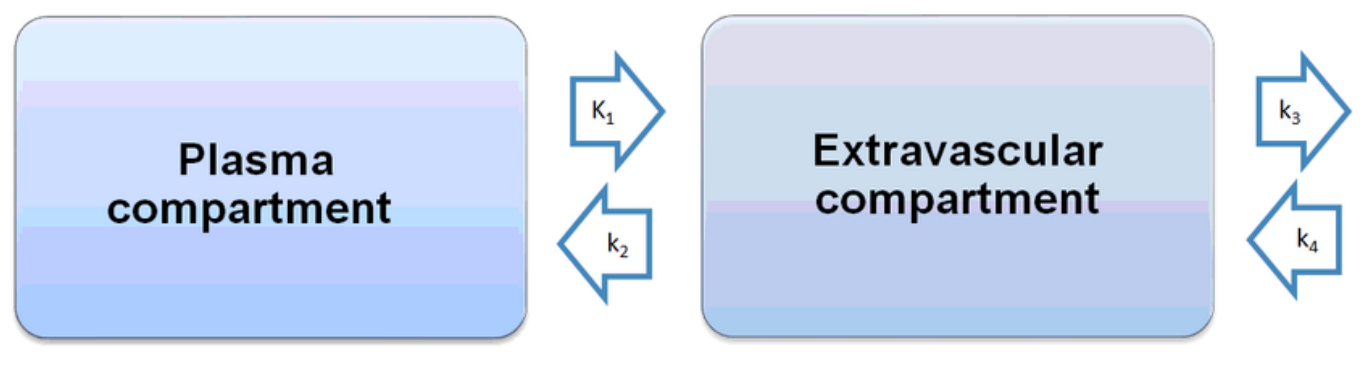

Bone compartment

\section{Figure 1}


Two-tissue compartment model (7)

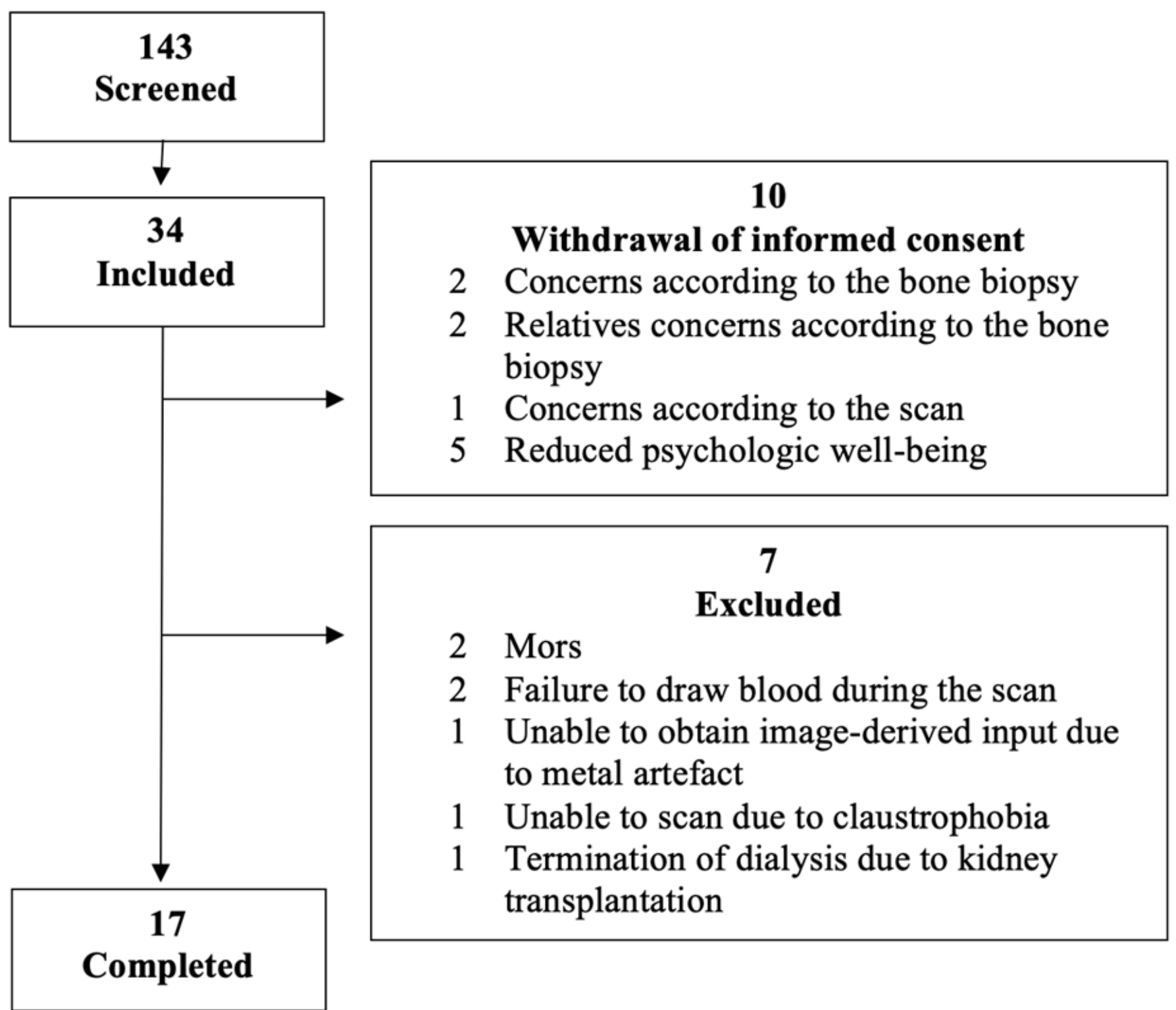

Figure 2

Flowchart of participant recruitment. Patients were additionally screened to participate in a bone biopsy as part of the complete study. Concerns regarding the bone biopsy contributed largely to the large withdrawal of consent seen in this study. 

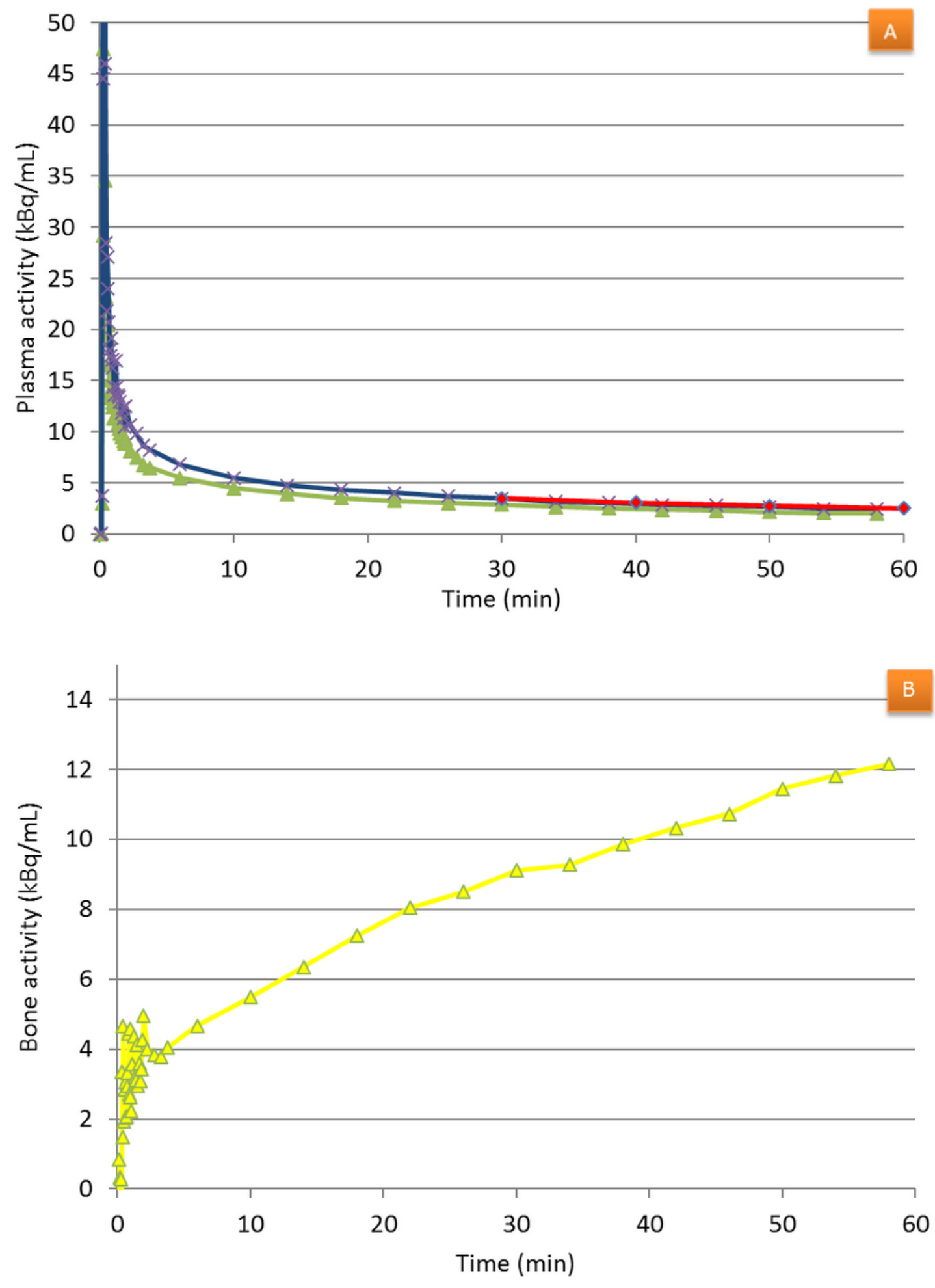

\section{Figure 3}

Example data curves obtained in the present study. 3a) Green line: non- $\beta$-corrected IDAIF obtained from left ventricle. Red line: The exponential obtained from ve-nous blood samples at 30, 40, 50 and 60 minutes. Blue line: $\beta$-corrected IDAIF obtained from left ventricle. 3b) Bone TAC obtained from a VOI in thoracic vertebra 9. Noise is present in the initial part of the curve. 


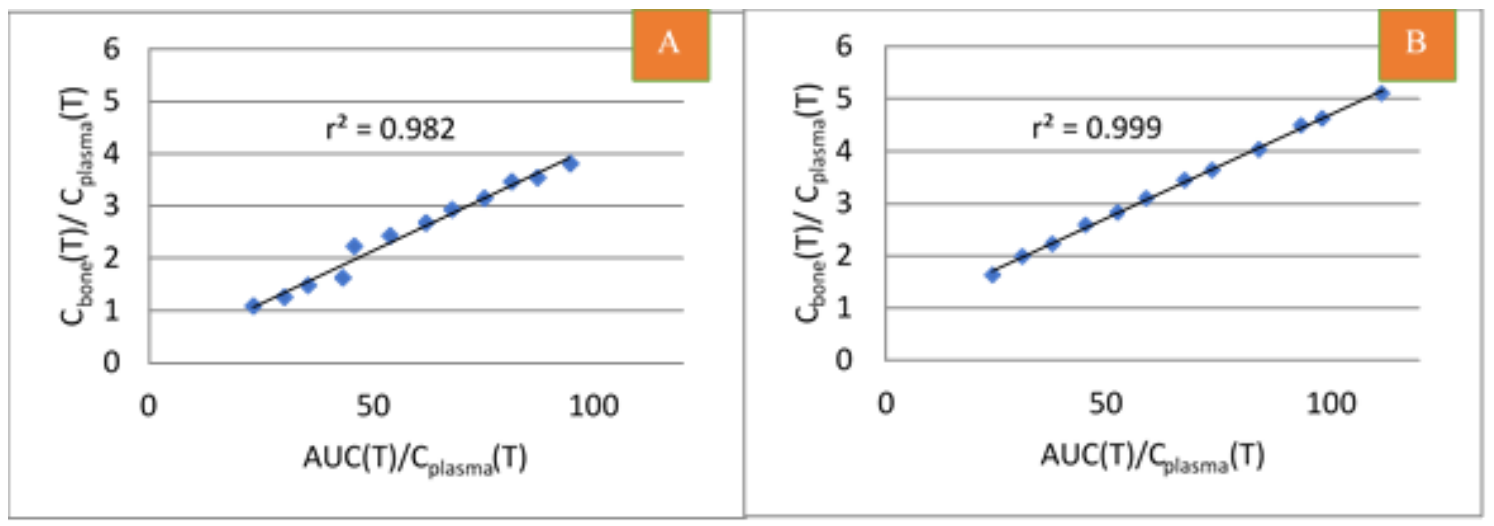

\section{Figure 4}

Correlation of dynamic Patlak coordinates using IDAIF. a) The lowest correlation coefficient found at participant no 2, vertebrae th9. b) The highest correlation coef-ficient found at participant no. 21, vertebra th10.
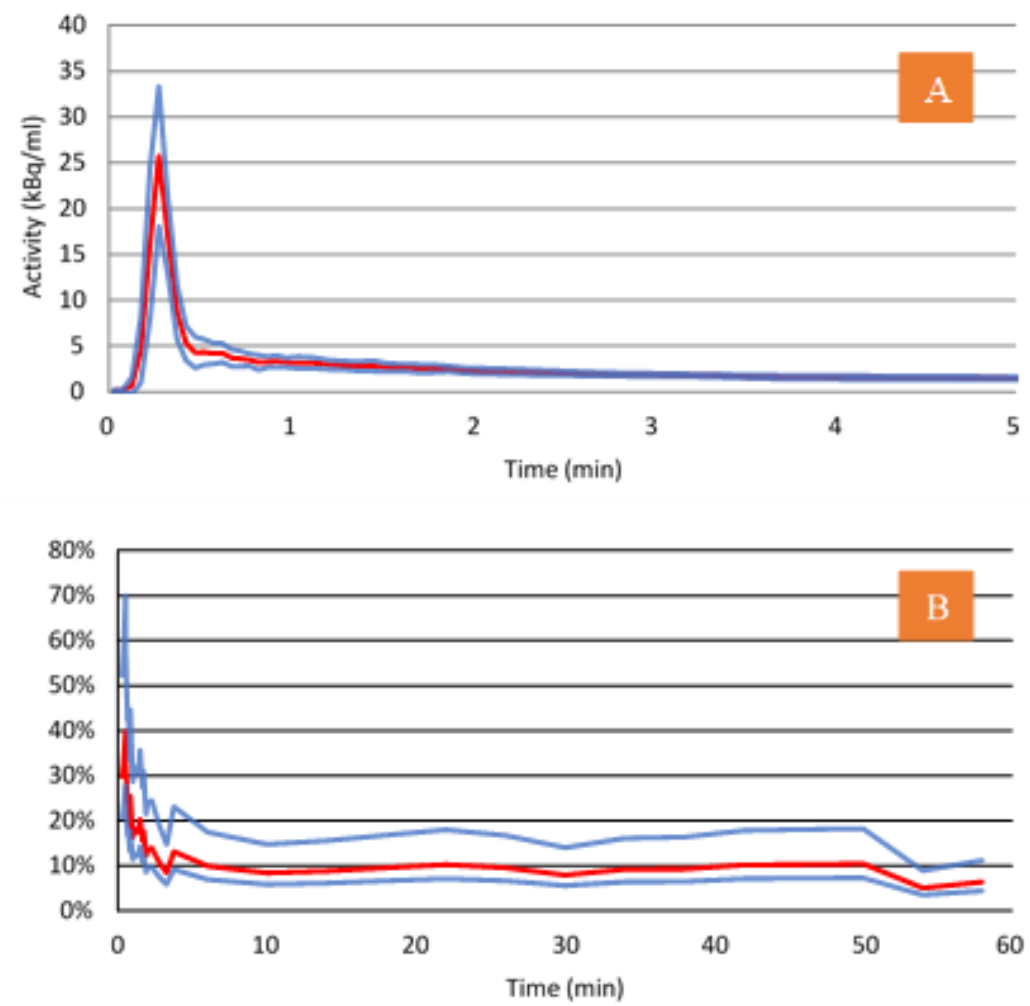

\section{Figure 5}

a) Population residual curve (red line) \pm 1 SD (blue lines). All curves are normalized to a reference activity of $150 \mathrm{MBq}$. b) The corresponding population SDs (red lines) plotted as the percentage coefficient of variation obtained by dividing the SD by the population residual curve with $95 \%$ confidence intervals (blue lines) estimated using the chi $^{2}$ distribution 

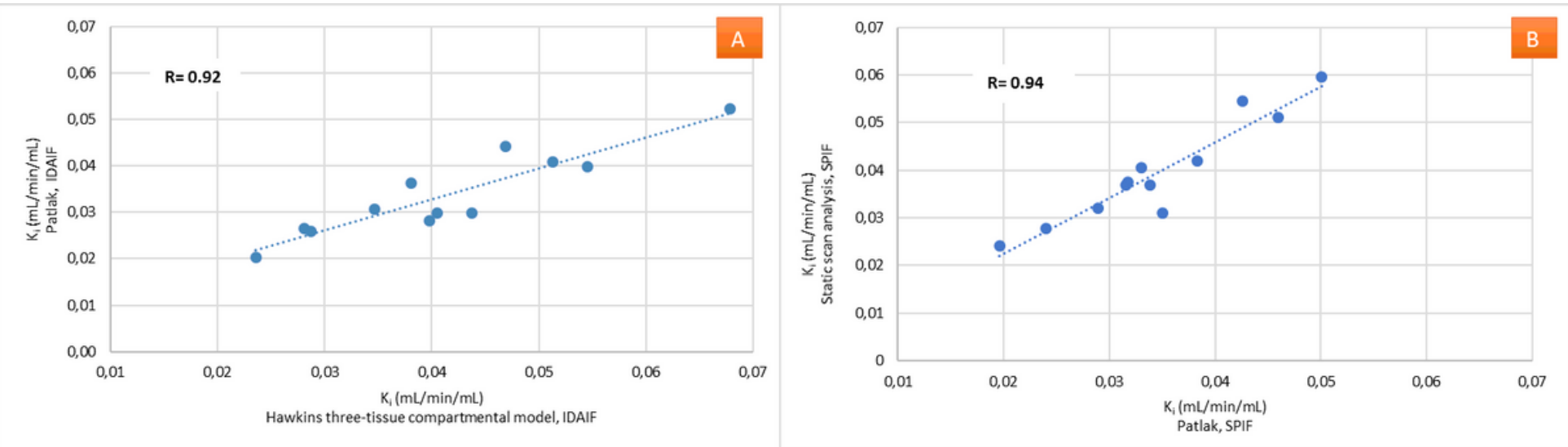

\section{Figure 6}

a) Correlation between mean Ki-values obtained by non-linear regression analysis and Patlak analysis. b) Correlation between mean Ki-value obtained by Patlak analysis of dynamic scan and mean Ki-value obtained by static scan
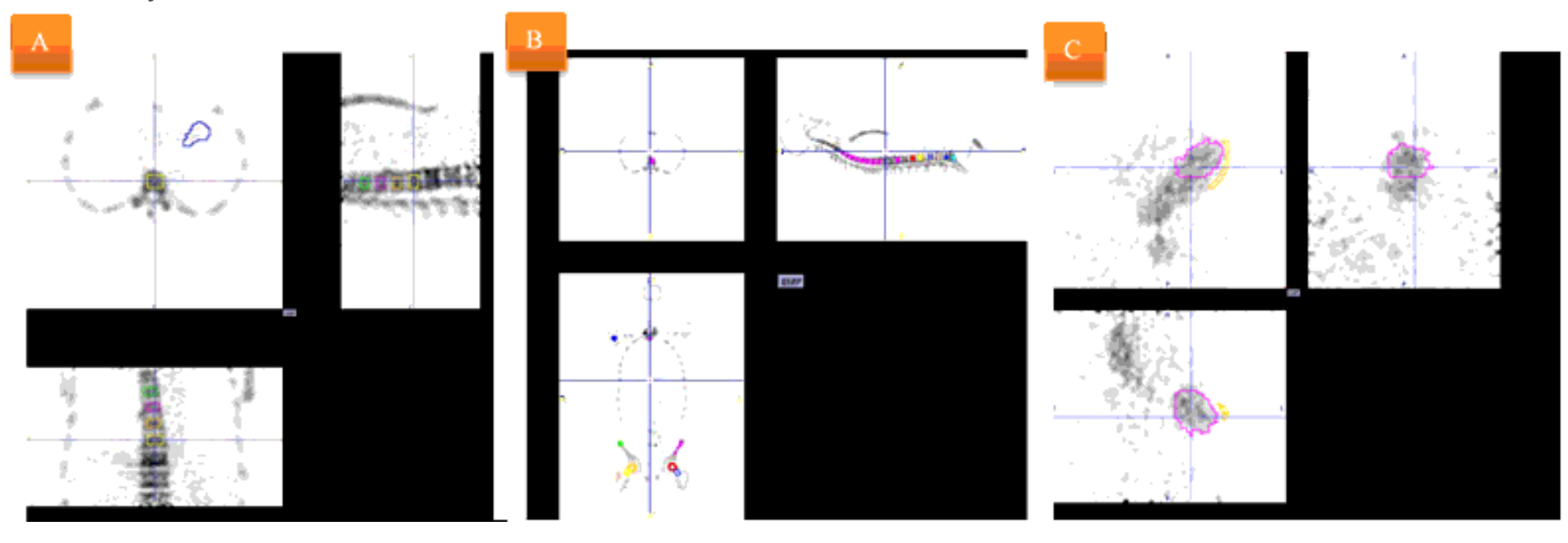

Figure 7

a) FOV from a dynamic 18F-NaF PET/CT showing VOIs to obtain bone TACs in vertebrae Th7-10 and a VOI in the left ventricle of the heart (LV) to ob-tain the image-derived input function. b) The whole-body $18 \mathrm{~F}-\mathrm{NaF}$ $\mathrm{PET} / \mathrm{CT}$ with the possibility to make bone VOIs in the entire skeleton. c) A VOI placed in LV and a myocardial VOI for $\beta$-correction 